\title{
"VIOLENCIA VISUAL: CONTRAINSURGENCIA Y TERRORISMO DE ESTADO COMO FACTORES DE LA GUERRA CIVIL SALVADOREÑA"
}

José Alfredo Ramírez Fuentes Universidad de El Salvador jose.ramirez1@ues.edu.sv

Recepción:

3 de noviembre de 2017

Aceptación:

24 de noviembre de 2017 


\section{RESUMEN}

La tecnología y la historia han estado juntas por mucho tiempo, pero los historiadores profesionales muy pocas veces reflexionan sobre la relación entre realidad, tecnología y nuestro oficio. Este ensayo intenta dar algunas ideas sobre cómo el análisis histórico puede ser realizado con fuentes poco convencionales. Como historiadores estamos acostumbrados a usar fuentes escritas, las fotos se usan solo para ilustrar los trabajos pero ¿qué pasaría si en realidad leyéramos las fotos como fuentes en sí mismas? ¿Cómo hacemos eso? Teniendo estas preguntas como punto de partida este texto girará en torno a tres temáticas: el terrorismo de estado, la fotografia y la memoria.

\section{Palabras Clave}

terrorismo, estado, violencia, fotografia, memoria,

\section{ABSTRACT}

Technology and history had been together since a long time, but as professional historians, just in very few occasions we think in the relationship of reality, technology and our craft. This essay attempt to give some insights in how historical analysis can be done with sources that are unconventional. As historians we are used to read written sources, photos are only for illustrate our works but, what will happen if we actually read photos as sources on their own? How do we do that? Taken this reflection as a point of departure this text will rotate around three topics: State terrorism, photography and memory.

\section{Keywords}

Terrorism, State, Violence, Photography, Memory. 


\title{
VIOLENCIA VISUAL: CONTRAINSURGENCIA Y TERRORISMO DE ESTADO COMO FACTORES DE LA GUERRA CIVIL SALVADOREÑA
}

\author{
José Alfredo Ramírez Fuentes \\ Universidad de El Salvador \\ jose.ramirez1@ues.edu.sv \\ “¿y cuándo vuelve el desaparecido? \\ Cada vez que lo trae el pensamiento" \\ Rubén Blades, Desapariciones
}

\section{Introducción}

El interés académico -desde el extranjero- por El Salvador creció considerablemente en los años finales de la década de 1970. Una vez comenzó la guerra, la mirada experta de los científicos sociales estadounidenses se clavó de lleno en el proceso salvadoreño. Varios factores contribuyeron a esa realidad: desde la historia se quería saber el porqué de ese conflicto, ${ }^{1}$ los politólogos buscaban entender, ${ }^{2}$ y después explicar, por qué las ideologías y el contexto de la Guerra Fría habían impacto tan fuerte en este pequeño país centroamericano, llevando a un enfrentamiento tan importante que incluso el gobierno estadounidense invertía grandes cantidades de dinero en

1 Thomas Anderson, El Salvador, 1932: Los sucesos políticos (San Salvador: Dirección de Publicaciones e Impresos, 2001); Robert Armstrong y Janet Shenk, El Salvador: el rostro de la revolución, (San Salvador: UCA editores, 1983); incluso estudios del siglo XIX salvadoreño iniciaron como proyectos que buscaban explicar los intensos conflictos políticos que provocaron la guerra civil de los años 80 en El Salvador; ver la introducción de Aldo Lauria-Santiago, Una república agraria (San Salvador: Dirección de Publicaciones e Impresos, 2002).

2 William Stanley, The Protection Racket State: Elite Politics, military extortion and civil war in El Salvador (Philadelphia:Temple University Press, 1996). 
la guerra salvadoreña. ${ }^{3}$ Pero un grupo de profesionales tomó aún más en serio su compromiso profesional y humano, estos fueron los fotoperiodistas que llegaron al país en medio del conflicto. ${ }^{4}$ Incluso directores de cine muy famosos han llevado la historia de estos fotógrafos a la pantalla grande en el contexto de la guerra civil salvadoreña. ${ }^{5}$ Las contribuciones de ese grupo de personas serán el principal insumo para el presente ensayo.

En la actualidad los intereses por conocer el pasado violento de El Salvador no han disminuido. Con una de las tasas de homicidios más altas del mundo, ${ }^{6}$ los salvadoreños aún se preguntan ¿Por qué somos tan violentos? ¿Por qué naturalizamos la violencia como algo cotidiano y "normal"? quizá la respuesta más simple es la que mejor se ajusta a este caso: los salvadoreños han estado rodeados y han reproducido la violencia por muchas décadas. ${ }^{7}$ Una de esas formas de violencia utilizadas en el pasado ha sido aquella aplicada por los gobiernos militares durante el siglo XX. No se busca en el presente escrito culpar solamente al estado por los problemas de violencia de la actualidad -como todo fenómeno social la violencia también tiene múltiples causas- pero sí se busca evidenciar dicha violencia estatal, la cual muchas veces se pone en entredicho. En la actualidad existe alternancia en el poder, pero para la década de 1960 y 1970 el solo pensar en que un partido de izquierda llegara al poder era motivo para ser reprimido por el

\footnotetext{
3 Breny Cuenca, El Poder intangible: La AID y el estado salvadoreño en los años ochenta (Managua: Ediciones CRIES, 1992).

4 Hay varios libros que retratan imágenes del conflicto, pero en el presente ensayo se utilizan dos: Adam Kufeld, Arnoldo Ramos and Manlio Argueta, El Salvador: Photographs by Adam Kufeld (New York:W.W. Norton and Company, 1990) y Harry Mattison, Susan Meiselas and Fae Rubenstein ed. El Salvador:Work of Thirty Photographers (New York:Writers and Readers Publishing Cooperative, 1983).

5 Salvador, dirigida por Oliver Stone (París: MGM home Entertainment, 2004), DVD.

6 Según Medicina Legal, en 2015 murieron por homicidio 6,656 personas y para 2016 hubo 5,280 casos.

7 Hay una extensa bibliografia sobre la violencia en El Salvador. Entre los ya clásicos se pueden mencionar: Patricia Alvarenga Venutolo, Cultura y ética de la violencia (San Salvador: Dirección de Publicaciones e Impresos, 2006) y de los más recientes: Benjamin Moallic, Las figuras del enemigo: alteridad y conflictos en Centroamérica (San Salvador: Dirección Nacional de Investigaciones en Cultura y Arte, 2012) y Adrian Bergmann y Óscar Meléndez, Violencia en tiempos de paz: conflictividad y criminalización en El Salvador (San Salvador, Dirección Nacional de Investigaciones en Arte y Cultura, 2015).
} 
Estado salvadoreño, con una fuerza solo comprensible dentro de la lógica de la Guerra Fría.

Historizar la violencia es en extremo complejo, especialmente por la falta de fuentes, pero también desde el punto de vista metodológico, pues plantea problemas relacionados con los límites del conocimiento humano. El historiador Greg Grandin afirma:

Lo que hace a la violencia, particularmente los actos de violencia política como la tortura, un singular, intraducible experiencia humana es [...] su inmunidad al entendimiento humano. [...] El dolor es una sensación humana que desafia la transmisión. No puede ser traducida a un verso, música o arte. Es inexpresable. Ya que el dolor y el mundo son absolutamente incompatibles, el ejercer dolor a través de la tortura tiene el efecto de [...] "de-construir" el mundo de la víctima. ${ }^{8}$

Teniendo esta reflexión en mente es preciso señalar que en El Salvador el proceso de reconstruir el pasado violento y traumático ha privilegiado el testimonio de los sobrevivientes o sus familiares y amigos, para conocer sus experiencias y tratar de llegar a explicaciones sobre los eventos vividos. ${ }^{9}$ Otro grupo de memorias que han surgido son las de los protagonistas de la guerra que se autodenominaron la vanguardia del pueblo y que también sufrieron episodios violentos por parte del Estado salvadoreño. Estos segundos testimonios, sin embargo, tiene la característica de ser pensados y relatados en la posguerra, un periodo que tiene por delante la promesa de mejores posicionamientos sociales para aquellos involucrados en el conflicto armado. ${ }^{10}$

Pero es necesario hacer una aclaración, las memorias -especialmente aquellas escritas y editadas- puede sufrir serias transformaciones o alteraciones, voluntarias o no, para eludir detalles importantes que pueden ser

8 Greg Grandin, «Introduction: Living in Revolutionary Times», Introducción en A Century of Revolution: Insurgent and Counterinsurgent Violence during Latin America's Long Cold War, eds. Gilbert Joseph y Greg Grandin (Durham y Londres: Duke University Press, 2010), 1-44.

9 Nora Méndez, De pseudónimo Clara (Guatemala: Letra Negra Editores, 2013).

10 Erik Ching, Stories of the Civil War in El Salvador a Battle over Memory (Chapel Hill: The University of North Carolina Press, 2016). 
esenciales para la investigación histórica profesional. ${ }^{11}$ Es más, mucha de la literatura sobre la guerra civil en El Salvador y fuera del país, está relacionada a la "versión" de la izquierda. La motivación del presente ensayo es observar y analizar la evidencia de la historia de El Salvador tratando de acercarse a la perspectiva de las víctimas y los testigos de la violencia estatal. No se pretende denunciar crímenes o señalar responsables, es un esfuerzo por entender algunos aspectos de lo que llamamos "la violencia visual" y el uso de estas imágenes -en el pasado y presente- para producir miedo y humillación, resignación o indignación, y su contribución a una cultura de la violencia. En una frase, se aspira a mostrarle al lector las implicaciones deshumanizantes de tomar fotografías de escenas violentas y las implicaciones de ese tipo de violencia que quedan como testimonios mudos, pero impactantes, para el presente histórico de cada generación.

Ya que la principal fuente de información para el presente texto son las fotografias de los fotoperiodistas estadounidenses, conviene señalar algunos puntos importantes. Primero, durante las décadas de 1970 y 1980 muchos fotoperiodistas llegaron al país. De estos la muestra tomada ha sido exclusivamente de los estadounidenses por ser ellos quienes publicaron sus imágenes en libros para el público en general. ${ }^{12}$ Segundo, estas fotos fueron tomadas desde una perspectiva "imparcial" en el sentido de no apoyar a ninguno de los bandos enfrentados, pero sí tenían un interés: retratar a las víctimas del conflicto y lograr capturar la mejor foto posible, aquella que los hiciera famosos. Esas imágenes eran tomadas con el fin de buscar que su trabajo incidiera en la opinión pública, que tuviera un impacto internacional o que fueran transmitidas en los noticieros estadounidenses para denunciar la violencia de un Estado intolerante. Con todas estas advertencias en mente,

11 Según Ching, hablando de su reciente trabajo sobre las memorias de la guerra civil en El Salvador: «Importa poco si los autores de mis fuentes están mintiendo, confusos, ignorantes [...] muchos de los narradores se han tomado libertades artísticas, ya sea consientes o no, por ejemplo el hecho de que hacen cosas como recrear de memoria diálogos palabra por palabra que ocurrieron décadas en el pasado». Erik Ching. Stories of the Civil War in El Salvador a Battle over Memory, 9.

12 Harry Mattison, Susan Meiselas and Fae Rubenstein eds., El Salvador:Work of Thirty Photographers. 
se debe aclarar que las fotografias de este ensayo han sido escogidas ya que reflejan una pieza de evidencia visual que brinda testimonio de momentos y eventos que el gobierno de la época probablemente negó. El terrorismo de estado y la violencia no son mencionados o aceptados por los gobiernos de turno, pero cuando son aceptados, se justifican afirmando que fueron acciones necesarias para combatir al "enemigo". Aunque eso significara pasar por encima de los derechos humanos.

\section{El inicio de la violencia}

Para el caso salvadoreño el inicio de la violencia estatal se puede colocar en la década de 1920, cuando los gobiernos de la dinastía de los MeléndezQuiñónez buscaban mantenerse en el poder por el mayor tiempo posible, con la excusa de respetar los periodos presidenciales. A inicios de la década de 1930 el gobierno de Arturo Araujo entró en crisis y fue entonces cuando el militarismo ascendió al poder a través del golpe de estado perpetrado por un grupo de militares jóvenes en diciembre de 1931. A partir de una estrategia política, premeditada o improvisada, el entonces Vice-presidente Hernández Martínez asumió la presidencia. ${ }^{13}$ Una de las primeras acciones de Hernández Martínez al asumir el poder fue sofocar lo que se presentó como un complot comunista en su contra. ¿En qué consistió ese movimiento? Un grupo de comunidades del occidente salvadoreño se organizaron en contra de las instituciones y figuras de poder local y en la media noche del 22 de enero de 1932 iniciaron el ataque de cuarteles -en Sonsonate y Ahuachapán - estaciones de telégrafo, comercios, casa de terratenientes y alcaldías. Este movimiento ha llegado a ser conocido en la actualidad como el levantamiento indígena-campesino de 1932, pero la realidad es que el levantamiento no se prolongó por más de una semana. En algunos municipios el ejército controló la situación en dos días.

13 Sobre los eventos alrededor del golpe de Estado de diciembre de 1931, ver: Guido Véjar, El ascenso del militarismo en El Salvador (San Salvador: UCA editores, 1980); Juan Mario Castellanos, El Salvador 1930 -1960:Antecedentes históricos de la Guerra Civil (San Salvador: Dirección de Publicaciones e Impresos, 2002) y Mariano Castro Morán, La Función política del ejército salvadoreño en el presente siglo (San Salvador: UCA Editores, 1983) 
Si el levantamiento de 1932 no duró más que pocos días ¿por qué se menciona como un ejemplo de violencia estatal? la violencia vino en las semanas siguientes. A partir del momento en que las tropas del ejército recuperaron el control de las localidades, se inició una etapa de persecución y fusilamiento de los supuestos involucrados en los eventos de fines de enero de 1932. La violencia de parte del gobierno de Martínez fue desproporcionada: de las decenas de sublevados que pudieron matar entre 50 y 100 personas, se asesinaron entre 8,000 y 10,000 personas en el lapso de unas cuantas semanas. El gobierno de la época no confirmó los números nunca y cuando hablaron de la "Matanza", los gobiernos militares -incluso aquellos posteriores a la dictadura de Martínez- se referían a ese evento como algo necesario, como una defensa de la patria o como un castigo ejemplar para la población.

A partir de los eventos de 1932 se creó la leyenda de la "causalidad comunista", ${ }^{14}$ es decir, los gobiernos militares en el siglo XX y los sectores sociales derechistas culparon al partido comunista de haber organizado y liderado a los sublevados de enero de 1932. En las décadas siguientes, todo aquel que criticara al gobierno era acusado de "comunista", siendo de inmediato desacreditado y puesto en peligro de represión estatal. Ese feroz anticomunismo del gobierno salvadoreño sirvió durante el periodo militarista para establecer una barrera de protección para los gobiernos militares, que los volvía inmunes a las demandas de la oposición política o de los ciudadanos salvadoreños. ${ }^{15}$ Fue así que por décadas la violencia en contra de los supuestos comunistas fue solamente discursiva, una amenaza que solo existía

14 Sobre el tema de 1932, hay mucho escrito, pero los mejores trabajos que argumentan sobre la causalidad comunista son: Erik Ching, Héctor Lindo-Fuentes y Rafael Lara-Martínez, Recordando 1932: la matanza, Roque Dalton y la política de la memoria histórica (San Salvador: FLACSO, 2010) y Erik Ching, Carlos López y Virginia Tilley, Las masas, la matanza y el martinato en El Salvador (San Salvador: UCA Editores, 2007), 35-36.

15 De acuerdo a William Stanley: «Exploro la idea de que los estados pueden operar «barreras protectoras, manipulando la apariencia de oposición de masas, o de hecho generándolas a través de inflexibilidad y brutalidad, para lograr asegurar las concesiones políticas y económicas vigentes por aparte de las elites sociales». William Stanley, The Protection Racket State: elite Politics, Military Extortion and Civil War in El Salvador (Philadelphia:Temple University Press, 1996), 13. 
en la imaginación de los gobiernos militares y era aplicada a la mente de los acusados. Una cura antes de la enfermedad.

A pesar de la realidad del país y del uso discursivo del anticomunismo, durante las décadas de 1960 y 1970 la población salvadoreña empezó a organizarse y protestar. Esta dinámica llevó a que por una parte los diferentes sectores de las derechas empezaran a creer que más seguridad era necesaria, es decir, que el elemento discursivo y preventivo ya no era suficiente.Y así sucedió, cada vez más recursos se invirtieron en el aparato de seguridad del Estado. Por otra parte, la ayuda estadounidense que llegaba a El Salvador en forma de proyectos de desarrollo social y económico como parte de la Alianza para el Progreso, tenía su contraparte, primero, en asistencia militar y más tarde, en inversión directa en armamento y entrenamiento. Cerca del año de 1980 el ejército salvadoreño tenía alrededor de 16,000 efectivos, los cuales sumados a los cuerpos paramilitares y policiales llegaban a 76,000 personas en promedio.

TABLA 1

\begin{tabular}{|c|c|}
\hline \multicolumn{2}{|c|}{ Fuerzas militares y policiales en El Salvador (c. 1980) } \\
\hline Fuerzas Armadas & 16,000 \\
\hline Guardia Nacional & 6,000 \\
\hline Policía Nacional & 5,000 \\
\hline Policía de Hacienda & 5,000 \\
\hline Policía Judicial & 2,000 \\
\hline Police Municipal & 2,000 \\
\hline Grupos paramilitares & 40,000 \\
\hline Total & $\mathbf{7 6 , 0 0 0}$ \\
\hline
\end{tabular}

Fuente: Instituto de Derechos Humanos, 1988. Citado por Aldo Lauria en: Aldo Lauria-Santiago, "The culture and Politics of State Terror and Repression in El Salvador," en When States Kill: Latin America, the U.S., and Technologies of Terror, Cecilia Menjivar (Austin: university of Texas Press, 2005).

Como se puede apreciar en la tabla 1 las Fuerzas Armadas solo eran una parte, pequeña, de una sociedad militarizada, que era el resultado de los es- 
fuerzos que los gobiernos militares habían sostenido por décadas para lograr un estricto control social. Cuando los primeros grupos guerrilleros aparecieron en la década de 1970, el Estado había preparado una amplia red de relaciones de control social por décadas. Así, los grupos paramilitares fueron los más numerosos como lo muestra la tabla que se inserta, pero no solo sus números son importantes, sino su estructura organizativa la cual funcionaba principalmente en el campo, donde la Guardia Nacional formaba parte en la selección, dirección y entrenamiento de estos grupos. A fines de la década de 1960 parte de estos efectivos paramilitares formaron una institución más definida llamada Organización Democrática Nacionalista (ORDEN), ${ }^{16}$ que a nivel local se organizaba en patrullas cantonales y se reportaba con los comandante departamentales, quienes a su vez informaban a la dirección del organismo y a la presidencia de la República.

En este contexto de una sociedad militarizada -desfiles militares, religión cívica con tintes militares, jerarquías institucionales rígidas, autoridad familiar patriarcal, etc.- cabe preguntarse ¿para qué necesitaba el Estado tanta protección? ¿Quién era el enemigo tan temido? Estas preguntas son extremadamente complejas y escapan al análisis del presente escrito, el objetivo es entonces mostrar una serie de fotografias que evidencian la materialización del discurso anticomunista: las víctimas de la violencia estatal.

\section{Imágenes de la violencia durante la Guerra Civil salvadoreña}

La aproximación que se plantea a las fuentes históricas visuales se divide en este ensayo en dos grupos. Primero, las fotografias que fueron imágenes fuertes y posiblemente traumáticas en su momento. Es decir, al pensar en el presente histórico de los fotografiados tenemos la certeza de que las escenas

16 Michael McClintock, The American Connection: State Terror and Popular Resistance in El Salvador (Londres: Zed Books, 1985). William Stanley, The Protection Racket State, y José Alfredo Ramírez Fuentes, «Aglutinando a las derechas: los primeros años del partido ARENA 19791984», en La Guerra Fría y el anticomunismo en Centroamérica, ed. Roberto García Ferreira y Arturo Taracena Arriola (Guatemala: FLACSO, 2017), 273-278. 
fueron vistas por muchos testigos; pero el lector, ubicado en otro momento de la historia las observa fuera de contexto, con la mirada de un presente distinto. Esto lleva, por supuesto, a pensar en la temporalidad y como esta afecta la fuente que presentamos. Estas son imágenes pasadas, pero que frente a ciertos ojos aún conservan un significado potente, aquellos testigos que aún sobreviven. El lector joven, que no vivió la guerra civil, probablemente encontrará poco significado en ellas. Segundo, se presenta una sección donde la fotografia es utilizada adrede como un objeto mnemotécnico, un objeto que despierta recuerdos y los dirige hacia una agenda o fin común para un grupo de personas en el presente, no en el momento en que fueron tomadas. Estas imágenes del segundo grupo muestran como en una fuente historia y memoria se convierten en una herramienta política y/o de denuncia social.

La primera de las imágenes refleja una práctica de la violencia estatal: el uso de los civiles como escudos humanos. La persona que está al frente y centro de la fotografia, de pie y camisa blanca, es un vendedor ambulante de paletas. En su vida cotidiana probablemente salía a las calles de San Salvador a tratar de vender lo suficiente para poder pegar sus gastos más básicos; un trabajo sin beneficios, ni prestaciones. Los cuatro policías no son tan diferentes de él en términos de posición social, con trabajos mal pagados y pocos beneficios. La diferencia real entre estos ciudadanos salvadoreños de finales de la década de 1970 era el hecho de que los policías utilizaban uniformes, armas y placas, símbolos que les otorgaban la autoridad de representar al Estado en la vida de todos los demás civiles, incluido en vendedor de la fotografía. Esa autoridad no les permitía, por supuesto, utilizar como "escudo humano" a esta persona de la cual desconocemos el nombre, pero que es reducido a un objeto. ${ }^{17}$

En la lógica de la vida cotidiana estas autoridades debían proteger al vendedor, eso decían sus lemas y los discursos de sus jefes. La violencia estatal y la violencia política se volvieron, poco a poco, parte de una cultura del miedo donde las acciones cotidianas eran acechadas por el temor e inse-

17 Harry Mattison, Susan Meiselas and Fae Rubenstein, ed. El Salvador:Work of Thirty Photographers (New York: Writers and Readers Publishing Cooperative, 1983). 
guridad, en medio de un clima de guerra civil. Como se observa en la foto, el rostro del vendedor es ejemplo vivo de esas relaciones de poder, donde lo más preciado de los actores históricos es amenazado: su vida.

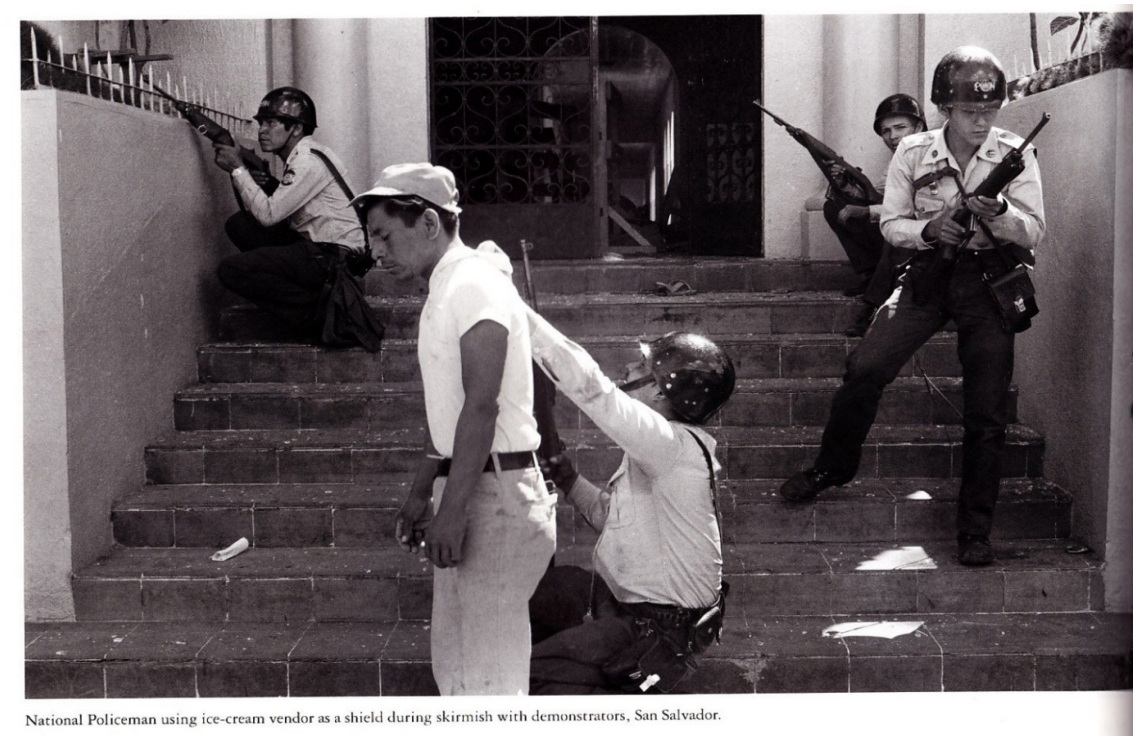

San Salvador, octubre de 1979.

La segunda imagen es parte de las operaciones de seguridad realizadas por la Guardia Nacional. La diferencia de uniformes y cascos era una característica de los cuerpos de seguridad en el campo. Las personas en el camión no son delincuentes, no son comunistas, son personas comunes tratadas de la peor manera posible. En la fotografia se observa un grupo de cuerpos acostados unos sobre otros y la pose de los agentes de los cuerpos de seguridad viéndolos de forma amenazante. El error de estas personas, por el cual estaban siendo apresados, era haber estado reunidos en una sede del Partido Demócrata Cristiano. En el momento que se redactan estas líneas es prácticamente imposible saber el paradero de estas personas, pero la imagen muestra que la llamada democracia de los gobiernos militares era nada más una herramienta discursiva, pues no se toleraba ni permitía estas actividad que eran entendidas como indisciplina y protestas. 
Si se presta atención a la vestimenta y zapatos de las personas en el piso del camión, se puede observar gente de las capas medias y trabajadoras de la sociedad salvadoreña, los cinco oficiales que aparecen en la foto están de nuevo abusando de su poder -como en la foto anterior- intimidando a los ciudadanos. Para acentuar su presencia, todos los oficiales llevan ametralladoras en sus manos y su dedo muy cera del gatillo, en caso que alguna de las personas llegara a intentar retar su autoridad. ¿Por qué el maltrato exagerado hacia los civiles? ¿Por qué la autoridad que se supone debía cuidarlos los trata como objetos indeseados? son preguntas que las fotos no responden, pero sí ayudan a pensar en esas inquietudes. De nuevo cabe señalar que las personas en la foto pertenecían a sectores sociales no muy distintos y la violencia y cultura del miedo se imponían una vez más.

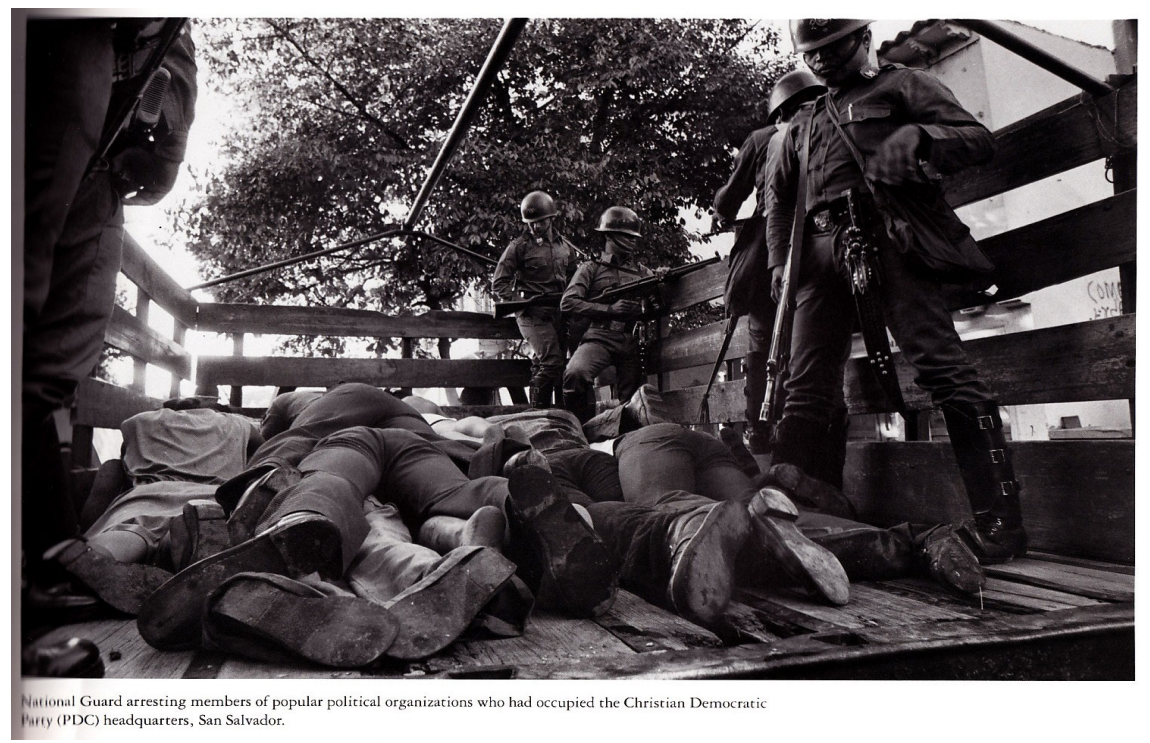

San Salvador, 1979

La tercera imagen muestra que uno de los miembros del a Guardia Nacional, estos agentes custodiaban por lo general en parejas, en la fotografia se muestra a uno de ellos llevando a un supuesto simpatizantes de la guerrilla detenido. En la mente de la mayoría de personas y de testigos durante 
la guerra, los miembros de la guerrilla debían ser capturados en acción, en combate, donde no quedaba duda que esa persona pertenecía a los insurrectos. Pero en el caso de este hombre, en primer plano en la fotografia, era acusado de ser un "supuesto" miembro de la guerrilla. ${ }^{18}$ En la fotografia también se observan cuatro testigos que están mirando a la persona arrestada, mismo que viste una camisa y unos jeans, en sus pies se aprecian un par de sandalias rústicas conocidas popularmente como caites, para proteger sus pies de las piedras del camino. Su vestimenta, por lo tanto, no muestra ninguna identificación con un partido de oposición, ni con grupos guerrilleros.

Uno de los cuatro testigos es un niño de menos de 10 años de edad, quien observa la escena con asombro. Este niño, desde muy temprana edad es testigo de la violencia estatal -la represión- que amenaza a sus familiares y a su comunidad, a la vez que es víctima de la violencia social y del miedo. El paisaje que se identifica en la imagen es una zona rural, donde los habitantes habían tenido sueños de una reforma agraria desde muchos antes de 1980. Irónicamente, el Estado había reprimido a los simpatizantes de esa reforma, hasta que en 1970 el presidente Sánchez Hernández anunció su realización a manos de su gobierno. Ese proyecto no fructificó pero 10 años después, la reforma se llevó a cabo bajo la Junta de Gobierno que reemplazó a los militares en el poder, con el respaldo de los Estado Unidos. Para el momento en que la foto fue tomada, la Reforma Agraria estaba siendo ejecutada.

18 Harry Mattison, Susan Meiselas and Fae Rubenstein, ed. El Salvador: Work of Thirty Photographers, 1983. 


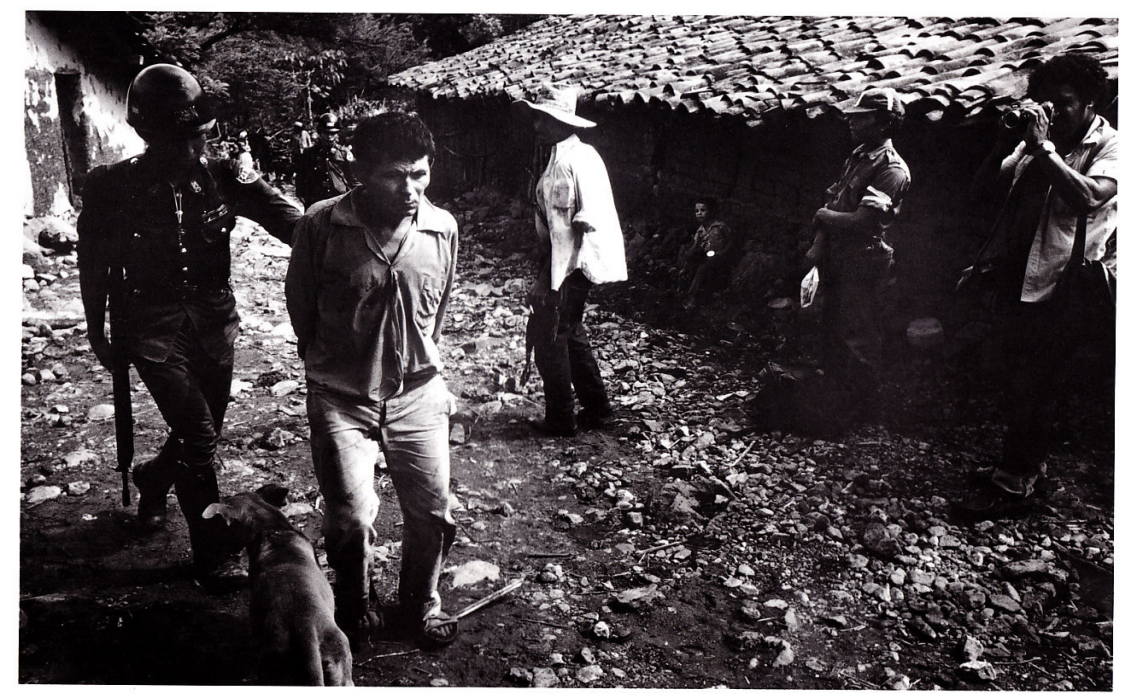

National Guardsman arresting a suspected guerrilla, Chalatenango.

Zona norte de El Salvador, departamento de Chalatenango, abril de 1980.

La cuarta fotografia es muy curiosa, ya que representa a un grupo de civiles huyendo de un ataque perpetrado por los cuerpos de seguridad del Estado. La imagen es única ya que muestra movimiento, muchas de las personas retratadas son mujeres cargando bolsas. De nuevo, similar al caso anterior, el paisaje es rural, con muros de casas en malas condiciones, despintadas, mostrando pobreza en la zona. En la parte central y abajo de la foto se puede apreciar la cabeza de un miembro de la guerrilla aún en la trinchera. La imagen retrata parte un de las dinámicas más traumáticas de las poblaciones rurales salvadoreñas en el norte y oriente salvadoreño, las llamadas "Güindas", momentos en que los miembros de las guerrillas evacuaban a los habitantes de una población para llevarlos a las montañas, protegiéndolos y protegiéndose a la vez de las acciones del ejército salvadoreño. 


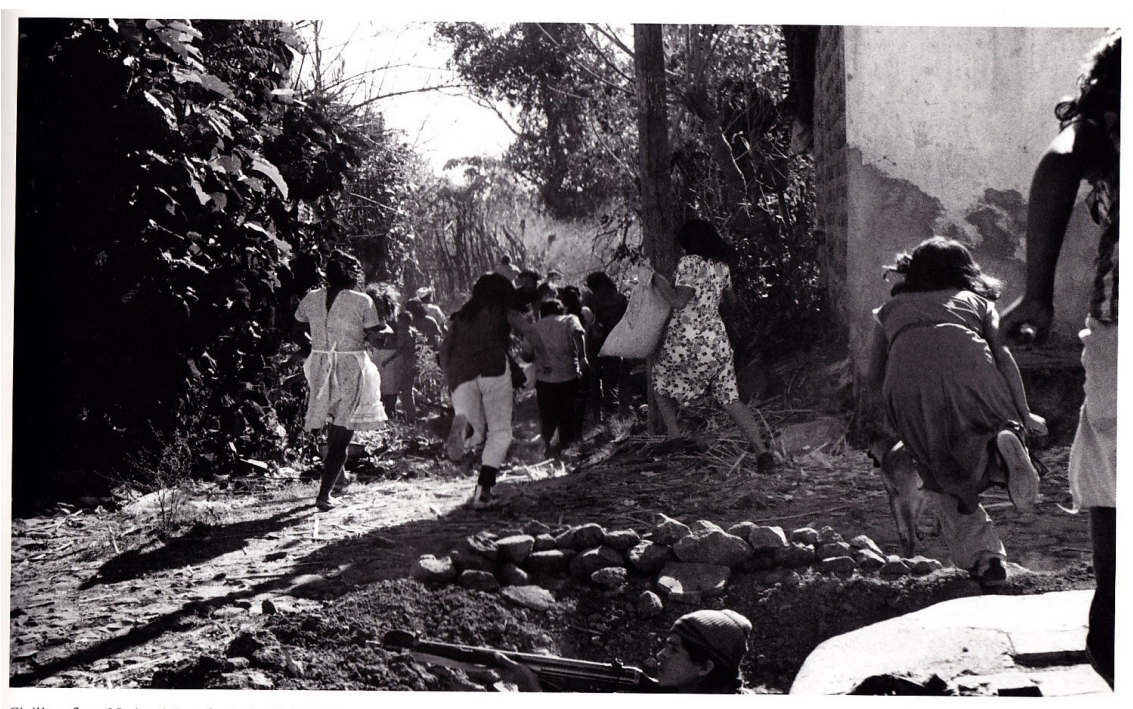

Civilians flee a National Guard attack, San Lorenzo.

San Lorenzo, 1981.

Las siguientes fotografias son muy impactantes, por lo que se ha recurrido a eliminar ciertas partes de esas imágenes. Muestran hechos en los que la policía y los militares negaron su participación. Aún no está claro quién atacó a estas víctimas -y el presente texto no busca identificar a los culpables- pero en su momento relatos, libros e incluso el informe de la comisión de la verdad acuso a los supuestos "escuadrones de la muerte" de ser los responsables de los excesos mostrados en las imágenes. Se entiende además que los grupos guerrilleros atacaban objetivos civiles, cuando estos eran empresarios o políticos importantes, y no a los ciudadanos comunes. Independientemente de quien haya cometido estos crímenes, lo importante a notar es la brutalidad con la que fueron atacadas estas personas y como sus cuerpos fueron colocados en público para despertar temor entre la población civil.

En la primera de las siguientes imágenes se observan los cuerpos sin vida de dos mujeres, con sus manos atadas a la espalda, y abandonadas a un lado de la carretera. En esta fotografía no se puede identificar un paisaje 
claro, pero de acuerdo a su descripción, estos cuerpos fueron encontrados en la carretera de Comalapa, la cual conecta la ciudad capital de San Salvador con el aeropuerto internacional de El Salvador, un espacio donde muchas personas e incluso los extranjeros que llegaban al país podían ver a las víctimas.

La segunda imagen que se muestra a continuación también fue toma a la orilla de la calle, esta vez en Chalatenango, al norte del país, donde la guerrilla tenía ya para 1981 un fuerte presencia y control territorial. La imagen muestra a seis soldados de pie frente a cinco cuerpos sin vida. Las víctimas están mutiladas y sus miembros son expuestos en la fotografia, los cuerpos a la derecha e izquierda de la foto muestran heridas profundas probablemente de machetes en el pecho.

Ambas imágenes son fuertes en contenido y significado. Las dos fotografias de los cadáveres son testimonio de la violencia presuntamente Estatal, en este caso, incluso de grupos paramilitares encubiertos por los órganos del Estado, mismos que nunca fueron reconocidos o perseguidos como delincuentes. En el primero de los casos mostrados, las imágenes son fuertes por que las víctimas son mujeres, las cuáles eran víctimas de torturas y violaciones, antes de ser asesinadas, aun cuando ellas no participaban activamente en las batallas o enfrentamientos entre ejército y guerrillas. En la foto de los soldados mostrando a los guerrilleros asesinados, estos muestran los cadáveres como trofeos, o como evidencia de su trabajo en contra del enemigo comunista. Este uso de los cadáveres para influir temor en la población ha sido estudiado y analizado por varios autores, quienes han demostrado el uso de la muerte como una herramienta de control social y de intimidación hacia la población en diferentes momentos de la historia de la humanidad. ${ }^{19}$ Así, podemos entender que los cuerpos mutilados de las víctimas de la violencia eran dejados en lugares públicos por grupos

19 Se pueden citar dos autores, el ya clásico: Michel Foucault, Vigilar y Castigar: el nacimiento de la prisión (México: Siglo XXI, 2009), publicado por primera vez en francés en 1975. Y el más novedoso trabajo de Vincent Brown, en el que define la necromancia como: «La manipulación de los muertos con el propósito de moldear acciones y eventos [...] Al invocar el poder de los muertos, ya sea como una advertencia para los rebeldes, como una fuerza de otro mundo, o como un ejemplo de martirio, los vivos hacen que el embrujado y terrorífico pasaje de la existencia espiritual se manifieste en los conflictos espacio-temporales». Vincent Brown, The Reaper's Garden (Massachussets: Harvard University Press, 2010), 130-131. 
paramilitares, y supuestamente por el ejército, como una lección para que la población no apoyara a la guerrilla, ni se manifestara en contra de las instituciones que representaban.

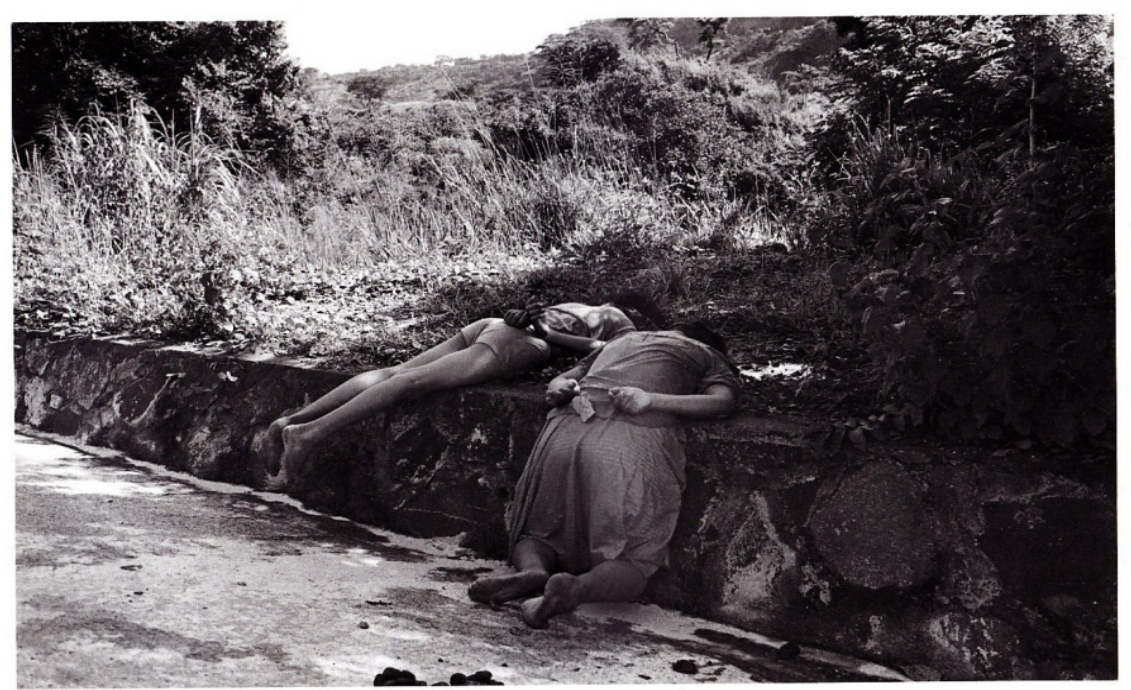

Two young girls found alongside the highway to Comalapa Airport.

Carretera de Comalapa, 1981.

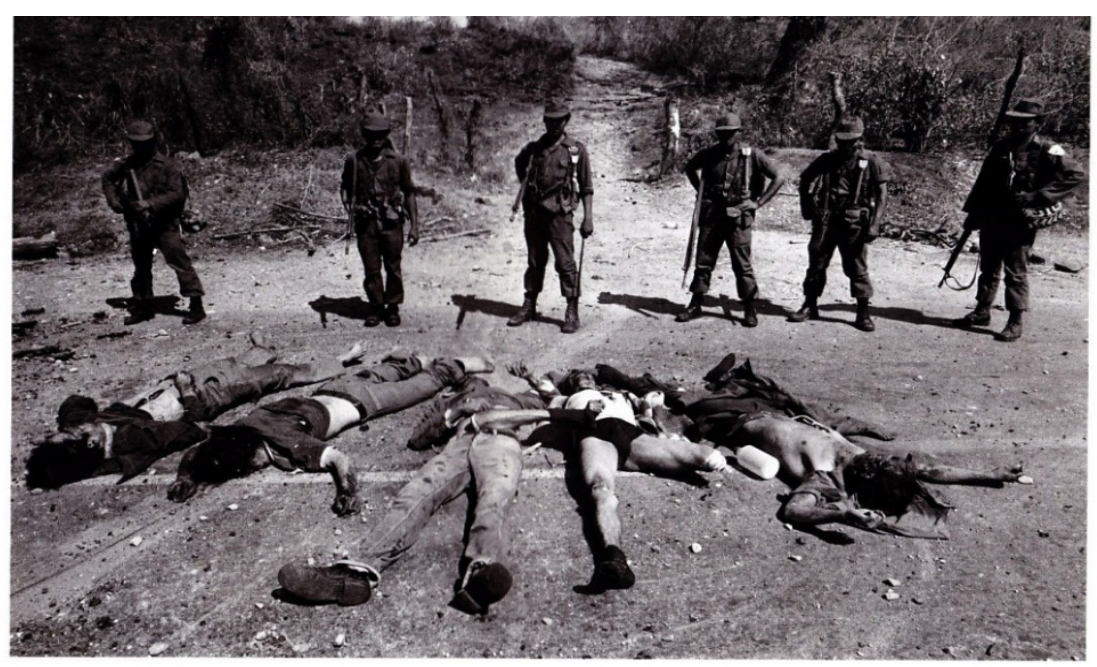

Soldiers with their mutilated victims, Chalatenango.

Chalatenango, 1981. 


\section{La violencia visual, una propuesta}

Por violencia visual se entiende toda aquella representación de la realidad que refleje una acción violenta del estado hacia la población civil; pero que además, en otra temporalidad y espacialidad, generan reacciones concretas hacia esas imágenes: demandas, duelos, conmemoraciones. El terrorismo de Estado y la represión son fenómenos característicos de estados autoritarios y militarizados que buscan contener a aquellos habitantes que consideran sus enemigos, aunque en muchas ocasiones esos opositores no son claramente identificables. En el caso de las imágenes identificadas arriba, es posible pensar en el referente dentro de la imagen, la fotografía en sí y el público. Este último grupo de personas pueden ser divididos en dos: el público que atestiguó las escenas retratadas en el presente histórico en que fueron tomadas y aquellas que las aprecian a la distancia temporal, es decir días, meses o años después de haber sido tomadas. ${ }^{20}$

Conviene aquí explicar, en primer lugar, que se entiende por el referente -mencionado en el párrafo anterior- en la fotografia, es la cosificación de un momento que refleja la realidad vivida. En este caso puede ser entendida como una simple denuncia sobre los abusos de poder de los cuerpos policiacos y paramilitares. Esa violencia se queda en el espectro visual fotográfico como prueba de hechos concretos: el arresto de ciertas personas, los abusos de poder de los cuerpos de seguridad del estado y la detención de campesinos sin una razón evidente. Un rasgo importante es que la ideología anticomunista del Estado se expresó a través de estas acciones violentas, aunque no fueron los ideólogos, ni los políticos quienes aplicaban esa violencia física, sino los miembros de los grupos policiacos y paramilitares. Estas personas eran quienes ejercían la violencia directamente hacia la población civil y los sospechosos de ser miembros de la guerrilla, personas que no estaban muy lejos de la realidad y posición social de los detenidos y asesinados.

20 Las ideas relacionadas a los actores sociales involucrados en la creación de las fotografias se obtienen de: Roland Barthes, Camera Lucida: Reflections on Photography (New York: Hill and Wang, 1981), 9. 
En segundo lugar, se puede hablar del fotógrafo y parte del público. Este último grupo de personas eran testigos del momento retratado, gente que probablemente estaba inconsciente del contexto que se vivía y que trataban de darle sentido a las imágenes que veían. El fotógrafo, por su parte, era un extraño medianamente informado que buscaba fama o impactar en la opinión pública internacional, un activista político que denunciaba los abusos de poder en el país. Estos individuos eran contratados por agencias de noticias internacionales y su trabajo consistía en tomar fotos de la realidad, la cotidianidad, evidencia o testimonio visual de los problemas que podían llegara a ser una noticia sensacional. Estas personas - público y fotógrafos extranjeros- junto con los salvadoreños que nacieron durante la guerra y después de ella, son parte de la "economía visual" de las imágenes de la guerra civil salvadoreña. ${ }^{21}$ Esta reflexión lleva a pensar en que todas estas fotografias llevan un determinado punto de vista, fijo; una intención, o perspectiva agregada por el fotógrafo y los editores de los libros que hicieron públicas dichas imágenes. ${ }^{22}$ No son solo mercancía, son productos de una realidad y de una "cultura del miedo" extrañas para las personas que aprecian y adquieren las imágenes. El hecho de que estas fotos lleguen a mercados de países extranjeros contribuyó, y aún lo hace, a la construcción de un imaginario colectivo de lo que fue la Guerra Civil en El Salvador.

Finalmente, cabe rescatar el hecho de que estas fotos son parte de un pasado nacional que contribuye a la construcción de una nueva sociedad que no vivó la guerra. Una comunidad imaginada de salvadoreños que pudieron haber olvidado ese pasado terrible. Por otra parte, estas fotos podrían ser parte de las lecciones del pasado para entender porque el país tiene tantos problemas y conflictos en el presente histórico que le toca vivir a cada generación de posguerra. Con estas ideas en mente, es preciso que la gente que está viviendo la cultura del miedo y la violencia en el presente, echen un

21 Deborah Poole, Vision Race and Modernity: A Visual Economy of the Andean World (New Jersey: Princeton University Press, 1997), 8.

22 Las fotografias para este ensayo fueron tomadas de: Harry Mattison, Susan Meiselas and Fae Rubenstein, ed. El Salvador:Work of thirty photographers, 1983; y de Adam Kufeld, Arnoldo Ramos y Manlio Argueta, El Salvador: Photographs by Adam Kufeld, 1990. 
vistazo al pasado que ha contribuido a moldear la realidad actual ¿Cómo se muestran estas imágenes? ¿Quién o qué institución debe manejar estos materiales a fin de mostrarlo a las nuevas generaciones? son preguntas necesarias de pensar y que aún no tienen respuesta.

\section{Memoria e historia: el caso del arzobispo Romero}

En la década de 1970 el Estado atacó a los sacerdotes, mayormente católicos e influidos por la teología de la liberación, como objetivos clave de la guerra que estaba por comenzar. El problema para el ejército se identificó cuando los campesinos empezaron a reunirse y organizarse formando comunidades eclesiales de base. Durante el gobierno del último presidente militar, General Arturo Romero (1977-1979), cuatro sacerdotes católicos fueron asesinados por el ejército. Debido a estos asesinatos, el arzobispo y líder de la iglesia -el Arzobispo Oscar Arnulfo Romero- pidió, e incluso ordenó, que los militares cesaran la represión. ${ }^{23}$ Como resultado de sus peticiones desde el púlpito y de su liderazgo a nivel popular, así como de su involucramiento político, el arzobispo Romero fue asesinado mientras daba misa en marzo de 1980. Los detalles de su muerte aún no están del todo claros, pero la mayor parte de la opinión pública e investigaciones independientes sostienen que un escuadrón de la muerte lo asesinó, dirigido por un líder de la derecha política de la época. ${ }^{24}$ Desde ese momento su imagen se ha convertido en objeto de culto para una gran cantidad de población salvadoreña, sobre todo entre los católicos. Dos imágenes de su funeral, realizado en una plaza pública de San Salvador son muy sugerentes para el estudio de las imágenes. En la primera es posible ver la plaza "Gerardo Barrios" completamente abarrotada de personas que lamentaban la muerte del arzobispo. Todos esperaban poder ver el ataúd y el cuerpo de este personaje, para poder despedirse de él según la

23 La frase pronunciada fue: «Les suplico, les ruego, les ordeno en nombre de Dios: ¡Cese la represión!». Homilía del 23 de marzo de 1980.Ver: «Beatificación de Monseñor Romero», La Prensa Gráfica, visitado el 27 de octubre, 2017, disponible en: http://especiales. elsalvador. com/2015/beatificacion-romero/articulo034.asp

24 Carlos Dada, «Así matamos a Romero», El Faro, consultado el 27 de octubre de 2017, disponible en: https://www.elfaro.net/es/201003/noticias/1403/ 
tradición católica. La imagen en sí es impresionante: se logran apreciar cientos -o quizá miles de personas- esperando ver el cuerpo de quien llamaban "la voz de los sin voz".

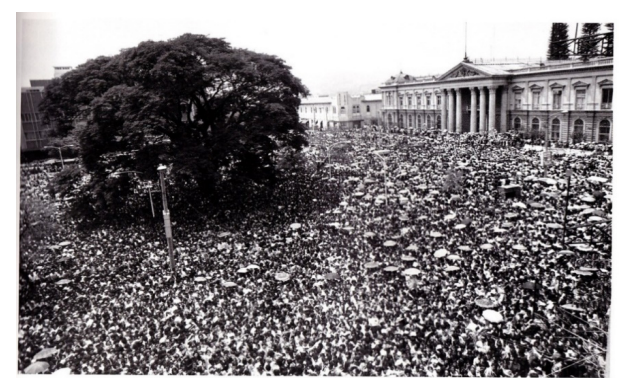

La foto a la izquierda fue tomada justo antes de que iniciaran los disparos por parte de los cuerpos de seguridad. La masacre en contra de la población civil fue realizada en el espacio público, donde los medios de comunicación pudieran llevar las terribles imágenes a los salvadore-

ños que no estaban físicamente presentes en ese evento. El objetivo era no solo disparar sobre las personas reunidas en la plaza, sino enviar un mensaje de miedo a los miembros de los grupos guerrilleros y a todos sus simpatizantes, algunos de los cuales estaban en medio de la muchedumbre.

Los eventos de ese día sucedieron repentinamente y la cantidad de personas era tan grande que de pronto todo se volvió un terrible desastre:

La solemne misa durante el funeral del asesinado Arzobispo de San Salvador Oscar Arnulfo Romero el 30 de marzo se volvió una estampida de pánico cuando una bomba explotó en la plaza frente a catedral, seguido de disparos. Algunas de las personas que estaban reunidos en la plaza empezaron a correr hacia la calle, mientras otros se arrojaron a las gradas enfrente de la catedral, trepando y abriendo camino sobre las otras personas frente a ellos, quienes estaban llenando el camino hacia el ataúd. Unas 24 personas murieron y 70 fueron heridas, la mayoría por asfixia y por haber sido pisoteados. ${ }^{25}$

25 No queda claro quién detonó la bomba mencionada al inicio del reporte, ni quiénes lanzaron los primeros disparos: «Bombs and Bullets Provoke Stampede at Archbishop's funeral» (Truth Commission) Created: 4/2/1980, accesed on 11/19/2010, disponible en: http://www.foia.cia.gov/docs/DOC_0000048984/DOC_0000048984.pdf. Documento disponible gracias a la ley de libertad de información (Freedom of Information Act, CIA). Traducción hecha por el autor. 
La segunda imagen del funeral muestra con gran precisión los últimos momentos de algunas de las personas que corrieron hacia la catedral de San Salvador pidiendo ayuda, las manos del niño y de la niña en la parte central-superior de la fotografia simboliza la necesidad de una mano que los ayude, probablemente lo que Barthes llama el "punctum" de la fotografia. ${ }^{26}$ Después de este evento, el arzobispo Romero se volvió un ícono para las personas que sufrieron por la guerra y también para aquellos desaparecidos durante la Guerra Civil.

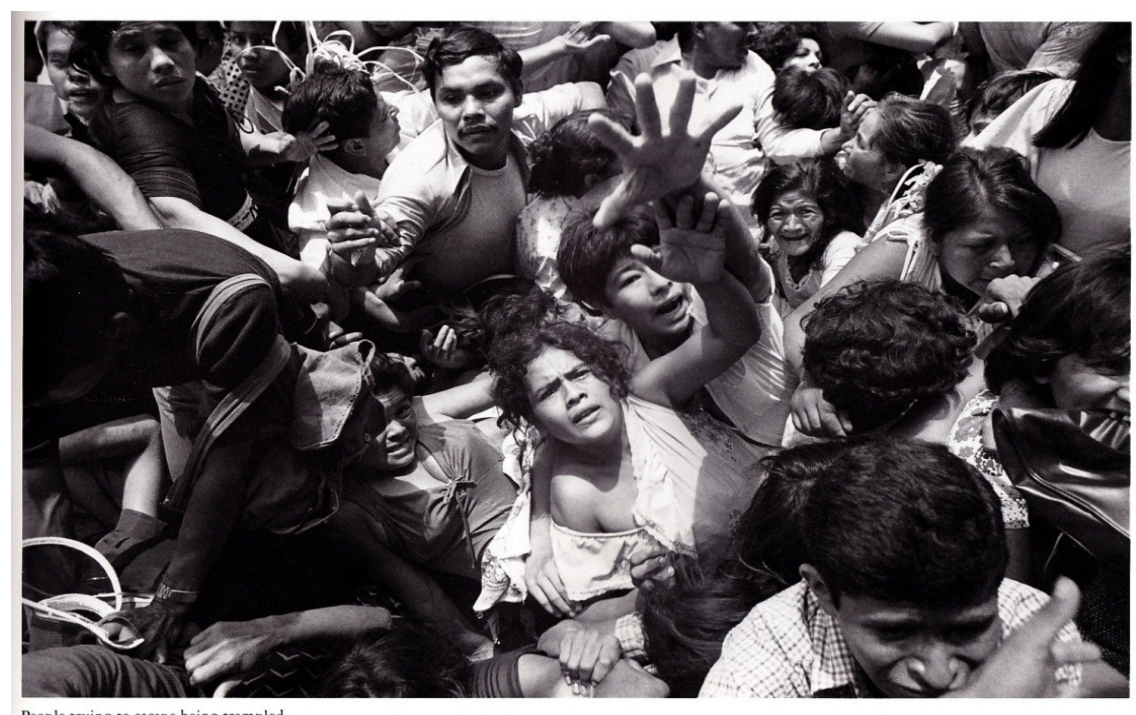

People trying to escape being trampled.

26 Para Roland Barthes, el «punctum» es esa parte de la fotografia que interrumpe el flujo de la imagen, es un aspecto que es captado y corta el escenario, llamando poderosamente la atención del espectador. Para Barthes, la fotografia está compuesta del «studium», que es todo aquello captado por la lente y que permite observar detenidamente determinada imagen $-\mathrm{y}$ a la vez identificarnos culturalmente y participar de ella a través de gestos, figuras, caras, poses, acciones - y además el «puctum»: «Es este elemento el que se eleva de la escena, es disparado como una flecha, y me perfora». Roland Barthes, Camera Lucida: Reflections on Photography, 1981, 26. 
Las últimas fotografias que se presentan a continuación, muestran la misma imagen -una que se ha vuelto icónica- del arzobispo Romero en dos escenarios distintos. A partir de ellas se puede observar que "en respuesta a la violencia, la represión y la impunidad que han sido una característica recurrente en la vida política de la región [latinoamericana] la fotografia ha emergido como un elemento de importancia central en la cultura material de protesta y lucha por la justicia". ${ }^{27}$ Como lo señala Noble las fotografias de los desaparecidos se han convertido en una herramienta, una forma de recordar y protestar -en toda Latinoamérica- en contra de la violencia estatal.

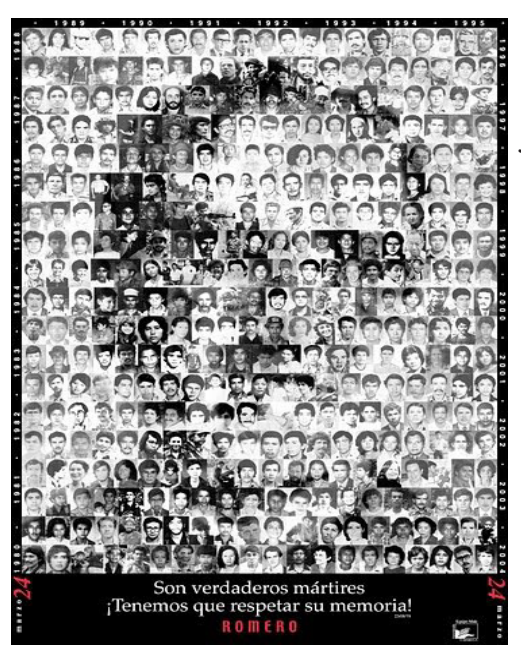

En una conferencia sobre memoria y fotografía, el historiador Daniel James, hace notar que las imágenes de las víctimas de las dictaduras militares en Argentina, han creado una posmemoria de los crímenes cometidos. Esa posmemoria -según James citando a Landbergse convierte en una memoria prostética para las nuevas generaciones, quienes no vivieron ni conocieron a las víctimas retratadas. Afirma James: "los acontecimientos y los problemas (recuerdos) deben ser representables para convertirse en una política. ${ }^{28}$ El mejor ejemplo de estas imágenes que se convierten en políticas del recuerdo para el caso salvadoreño es un mosaico de fotografias de varios desaparecidos de la guerra civil salvadoreña, que juntos forman la imagen del arzobispo Romero. La idea de que el arzobispo representa al pueblo, se convierte en la imagen del líder asesinado -que algunos llaman mártir-

27 Andrea Noble, «Family photography and the Global Drama of Human Rights» in Photography: theoretical Snapshots, J. J. Long, Andrea Noble and Edward Welch (New York: Routledge, 2009), 65.

28 Daniel James, «Fotos y cuentos: pensando la relación entre historia y memoria en el mundo contemporáneo» (Conferencia en el Centro de Documentación e Investigación de la Cultura de Izquierdas en Argentina, 23 de noviembre de 2010). 
representando a los desaparecidos del conflicto. La idea de representatividad también está contenida en la frase "renaceré en el pueblo", atribuida al Arzobispo Romero.

\section{Comentarios finales}

El presente ensayo es una contribución metodológica a la historia, en el sentido de reflexionar sobre la fotografia y su uso como fuente de información sobre el pasado. En este sentido se abordaron dos grupos de fotografias. En el primer grupo se seleccionaron fotos que retratan el trauma de las personas que sufren los abusos del poder estatal, son representados gráficamente como testimonio de un pasado que muchas veces es negado. Lo importante a señalar es lo valiosa que es la imagen fotográfica y lo peculiar de su contenido a diferencia de fuentes orales y escritas.

Por una parte la fotografia nos habla de tres temporalidades distintas, donde ha sido utilizada como referente de la realidad. Primero estaría el instante mismo en que es tomada y que se entiende como una imagen de denuncia que pretende ser 100\% fidedigno. En segundo lugar, está la temporalidad de su publicación y distribución, que generó en algún momento del pasado una opinión pública desfavorable al gobierno, y que llevó principalmente a la denuncia en favor de los derechos humanos, o incluso un apoyo a la guerrilla. Un tercer y último momento sería el presente desde donde se le observa como fuente histórica con características propias: ninguna fuente muestra visualmente el escenario de manera tan detallada, pero no es $100 \%$ fiel a la realidad, pues en la mayoría de los casos, la imagen habla desde la perspectiva del fotógrafo, quien es un personaje con intereses propios o corporativos -en el sentido de trabajar para agencias noticiosas internacionalesque se traducen en un enfoque o perspectiva de la realidad predeterminado.

Estas temporalidades, a pesar de sus diferencias, siguen conectadas pues eran parte de las escenas de la vida cotidiana durante la guerra civil salvadoreña. Aquellas personas que presenciaron esas escenas y la sociedad que sufrió el trauma del conflicto -en un sentido colectivo- han mutado de una violencia política cotidiana a una cultura de la violencia, donde el miedo, el rencor, la ira parecieran una constante diaria. 
En el segundo grupo de imágenes analizadas es importante señalar que las imágenes de las víctimas y líderes del conflicto armando -en El Salvador y en Argentina, y quizá en América Latina en general- son representaciones iconográficas que son rescatadas por familiares y amigos, hasta que se convierten en símbolos de protesta de grupos sociales que tienen objetivos políticos concretos que van desde las políticas de perdón y olvido, pasando por la justicia transicional o la retribución estatal, hasta llegar al uso electoral o propagandístico de las imágenes de líderes y víctimas. Cuando estas imágenes transitan del espacio familiar, íntimo, al espacio público, de la sociedad en general, sufren cambios que están relacionados a la memoria. Más en concreto, estos recuerdos "públicos" se vuelven una memoria prostética, es decir, recuerdos que no son propios de los actores históricos, sino transmitidos por los colectivos a nuevas generaciones que no tiene la experiencia histórica pero la aprenden en el espacio de lo público.

Por otra parte, la relación entre fotografia y memoria es muy importante y aquí solo se hará la siguiente reflexión: ambas son capaces de detonar recuerdos sobre acontecimientos traumáticos. Estas fotografias de los desaparecidos -casi siempre las fotos de carnets de identificación, o cédulas de identidad- tienen un espacio dentro del proceso de duelo y reconciliación, individual y colectivo, que también da espacio a conmemoraciones y la construcción de imágenes de mártires del conflicto. El duelo y la admiración serían entonces, respuestas culturalmente entendidas $-\mathrm{y}$ sobre esto falta mucha investigación- como necesarias para enfrentar el recuerdo de la violencia que se experimentó, una violencia que la memoria no deja morir. 


\section{REFERENCIAS BIBLIOGRÁFICAS}

Alvarenga Venutolo, Patricia. Cultura y ética de la violencia. San Salvador: Dirección de Publicaciones e Impresos, 2006.

Anderson, Thomas. El Salvador. 1932: Los sucesos políticos. San Salvador: Dirección de Publicaciones e Impresos, 2001.

Armstrong, Robert y Janet Shenk. El Salvador: el rostro de la revolución. San Salvador: UCA Editores, 1983.

Barthes, Roland. Camera Lucida: Reflections on Photography. New York: Hill and Wang, 1981.

Bergmann, Adrian y Óscar Meléndez. Violencia en tiempos de paz: conflictividad y criminalización en El Salvador. San Salvador, Dirección Nacional de Investigaciones en Arte y Cultura, 2015.

Brown, Vincent. The Reaper's Garden. Massachussets: Harvard University Press, 2010.

Ching, Erik. Stories of the Civil War in El Salvador a Battle over Memory. Chapel Hill:The University of North Carolina Press, 2016.

Cuenca, Breny. El Poder intangible: La AID y el estado salvadoreño en los años ochenta. Managua: Ediciones CRIES, 1992.

Grandin, Greg y Gilbert Joseph eds. A Century of Revolution: Insurgent and Counterinsurgent Violence during Latin America's Long Cold War. Durham y Londres: Duke University Press, 2010.

Kufeld, Adam, Arnoldo Ramos and Manlio Argueta. El Salvador: Photographs by Adam Kufeld. New York:W.W. Norton and Company, 1990.

Lauria-Santiago, Aldo. «The culture and Politics of State Terror and Repression in El Salvador» in When States Kill: Latin America, the U.S., and Technologies of Terror, Cecilia Menjívar. Austin: university of Texas Press, 2005.

Mattison, Harry, Susan Meiselas and Fae Rubenstein ed. El Salvador:Work of Thirty Photographers. New York: Writers and Readers Publishing Cooperative, 1983.

McClintock, Michael. The American Connection: State Terror and Popular Resistance in El Salvador. Londres: Zed Books, 1985.

Méndez, Nora. De pseudónimo Clara. Guatemala: Letra Negra Editores, 2013. Menjívar, Cecilia. When States Kill: Latin America, the U.S., and Technologies of Terror. Austin: University of Texas Press, 2005. 
Moallic, Benjamín. Las figuras del enemigo: alteridad y conflictos en Centroamérica. San Salvador: Dirección Nacional de Investigaciones en Cultura y Arte, 2012.

Noble, Andrea. «Family photography and the Global Drama of Human Rights», in Photography: theoretical Snapshots, J. J. Long, Andrea Noble and Edward Welch. New York: Routledge, 2009.

Poole, Deborah. Vision Race and Modernity: A Visual Economy of the Andean World. New Jersey: Princeton University Press, 1997.

Ramírez Fuentes, José Alfredo. «Aglutinando a las derechas: los primeros años del partido ARENA 1979-1984» en La Guerra Fría y el anticomunismo en Centroamérica, ed. Roberto García Ferreira y Arturo Taracena Arriola, (Guatemala: FLACSO, 2017), 273-278.

Stanley, Williams. The Protection Racket State: elite Politics, Military Extortion and Civil War in El Salvador. Philadelphia:Temple University Press, 1996. 